\title{
GAMBARAN PENGETAHUAN DAN SIKAP WARGA DESA SENANING KECAMATAN KETUNGAU HULU KABUPATEN SINTANG TENTANG PENYAKIT MALARIA KNOWLESI
}

\section{KNOWLEDGE AND ATTITUDE TOWARDS MALARIA KNOWLESI: A CASE STUDY AT SENANING VILLAGE, KETUNGAU HULU SUB- DISTRICT SINTANG DISTRICT}

\author{
Djalika $Z^{1)^{*}}$, Agus Fitriangga ${ }^{2)}$, Agustina Arundina Triharja Tejoyuwono ${ }^{3)}$, Diana \\ Natalia ${ }^{4)}$ \\ 1,2,3,4) Fakultas Kedokteran Universitas Tanjungpura, Jl. Prof. Dr. H. Hadari Nawawi, Pontianak \\ *email: djalikazulkarnain@student.untan.ac.id
}

Submit 28 Oktober 2020, Revisi 17 Desember 2020, Terbit 31 Desember 2020

\begin{abstract}
Malaria knowlesi was confirmed as an endemic zoonosis in Malaysian Borneo in 2004. The molecular analysis showed that $58 \%$ of malaria cases in Sarawak, Malaysia were caused by P. knowlesi. Because Senaning Village, Ketungau Hulu Subdistrict, Sintang Regency lies at the border with Sarawak, Malaysia, it is potential for this village to have a disease transmission from Sarawak. This study aimed to describe the knowledge and attitudes of the community towards malaria knowlesi. It was also designed to describe the respondent characteristics of Senaning Village, Ketungau Hulu Subdistrict, Sintang Regency. This study was an observational descriptive study. The sampling was done by purposive sampling technique. The instrument was a questionnaire with sample size of 93 respondents. The result of this study indicated that highest proportion of respondents were male (51.61\%), early adult age group 26-35 years (26.88\%), graduated from college (34.41\%), and farmers/laborers (34.41\%). The research respondents had a moderate level of knowledge (49,5\%) and attitude (68,8\%).
\end{abstract}

Keywords: Malaria Knowlesi, Knowledge, Attitude, Zoonosis

\begin{abstract}
ABSTRAK
Malaria knowlesi dikonfirmasi sebagai zoonosis endemik di Borneo Malaysia pada tahun 2004. Anaslisis molekular menunjukan bahwa 58\% kasus malaria di Sarawak, Malaysia disebabkan oleh $P$. knowlesi. Karena Desa Senaning Kecamatan Ketungau Hulu, Kabupaten Sintang merupakan desa yang berbatasan dengan Serawak, Malaysia, desa ini memiliki potensi terjadinya penularan penyakit. Tujuan penelitian ini adalah untuk mengetahui gambaran pengetahuan dan sikap serta karakteristik responden di Desa Senaning Kecamatan Ketungau Hulu Kabupaten Sintang tentang penyakit malaria knowlesi. Penelitian ini adalah penelitian observasional deskriptif. Pengambilan sampel dilakukan dengan teknik purposive sampling. Instrumennya adalah kuisioner dengan jumlah sampel sebanyak 93 responden. Hasil penelitian menunjukan bahwa distribusi proporsi dominan dalam penelitian ini jenis kelamin laki-laki $(51,61 \%)$, kelompok usia dewasa awal $26-35$ tahun $(26,88 \%)$, tamat perguruan tinggi $(34,41 \%)$, petani/ buruh $(34,41 \%)$. Responden penelitian ini memiliki pengetahuan cukup $(49,5 \%)$ dan sikap cukup $(68,8 \%)$.
\end{abstract}

Kata kunci: Malaria Knowlesi, Pengetahuan, Sikap, Zoonosis 


\section{PENDAHULUAN}

Malaria adalah penyakit yang disebabkan oleh anggota genus plasmodium (Faust \& Dobson, 2015). Singh \& Daneshvar (2013) mengemukakan bahwa manusia secara alamiah merupakan hospes untuk empat jenis plasmodium yaitu, $P$. falciparum, $P$. vivax, $P$. malariae, and $P$. ovale. Ambarita (2014) menyebutkan bahwa setelah kejadian malaria zoonotik ditemukan di berbagai negara di Asia Tenggara, $P$. knowlesi ditetapkan menjadi plasmodium ke lima yang menyebabkan malaria pada manusia.

Menurut Millar \& Cox-Singh (2015), Plasmodium knowlesi merupakan parasit yang ditemukan pada spesies Macaca fascicularis (kera ekor panjang) dan Macaca nemestrina (kera ekor babi), dan ditularkan ke manusia melalui nyamuk Anopheles leucosphyrus. Barber et al. (2017) menyatakan bahwa P. Knowlesi menyebabkan malaria yang sangat patogen dengan ambang pirogenik yang rendah.

Setiadi et al., (2016) menyebutkan bahwa Plasmodium knowlesi dikonfirmasi sebagai zoonosis endemik di Borneo Malaysia pada tahun 2004. Analisis molekular menunjukan bahwa 58\% kasus malaria di Sarawak, Malaysia disebabkan oleh $P$. knowlesi. Kasus $P$. knowlesi juga dilaporkan di Thailand, Filipina, Singapura, Vietnam dan Myanmar. Kasus $P$. knowlesi di Indonesia pertama kali dilaporkan pada 2010.

Faktor geografis dan faktor mata pencaharian penduduk di Provinsi Kalimantan Barat menjadi faktor risiko dari penularan penyakit malaria $P$. knowlesi di Desa Senaning. Badan Pusat Statistik Kabupaten Sintang 2019 menyebutkan bahwa Desa Senaning, Kecamatan Ketungau Hulu,
Kabupaten Sintang, berbatasan langsung dengan Serawak, Malaysia. Mata pencaharian utama masyarakat perbatasan sendiri umumnya berkebun karet (Hazrian, 2011). Hal ini berhubungan erat dengan pemanfaatan area hutan sebagai lahan perkebunan yang mengakibatkan makin dekatnya kontak antara manusia dengan primata yang berdampak pada meningkatnya potensi penularan penyakit zoonosis. Asmara (2019) berpendapat bahwa laju penyebaran $P$. knowlesi dapat lebih cepat sebagai dampak arus perpindahan penduduk antar negara. Studi kasus yang dilakukan oleh World Health Organization \& University of California (2015) melaporkan bahwa migrasi penduduk Indonesia yang mencari pekerjaan di sektor perkebunan dan penebangan hutan ke Sarawak dan Sabah terjadi setiap hari. Notoadmodjo (2012) menyebutkan bahwa pengetahuan merupakan domain yang sangat penting dalam membentuk perilaku seseorang. Perilaku yang didasari oleh pengetahuan akan berlangsung permanen, sedangkan sikap adalah respon kognitif terhadap suatu objek. Pengetahuan dan sikap yang tepat mengenai $P$. knowlesi dapat membantu mencegah dan mengidentifikasi dini penyakit malaria yang disebabkan $P$. knowlesi. Paul M. Arguin (2013) menyebutkan bahwa pengetahuan dan sikap dalam pencehagan malaria knowlesi meliputi pencegahan terhadap gigitan nyamuk, seperti mengetahui kebiasaan nyamuk Anopheles yang menggigit manusia pada malam hari, sikap dan prilaku positif terhadap penggunaan kelambu, insektisida spray, pakaian tertutup dan repelen pada bagian tubuh yang tidak ditutupi pakaian.

Menurut data Profil Kesehatan Provinsi Kalimantan Barat pada tahun 2017, Kalimantan Barat pada tahun 
2015 telah memasuki tingkat low cumulative incidence dengan API $<1$. Angka kesakitan malaria di Kalimantan Barat pada tahun 2017 adalah 0,03 per 1.000 penduduk. Profil kesehatan Kabupaten Sintang tahun 2015 menunjukkan bahwa Kabupaten Sintang termasuk klasifikasi endemis rendah. Keadaan tersebut mempengaruhi gambaran pengetahuan dan sikap masyarakat tentang malaria. Suharjo (2015) menyebutkan bahwa penduduk di daerah endemis tinggi dan endemis sedang malaria umumnya memiliki pengetahuan yang baik terhadap penyakit malaria. Menurut Forero et al. (2014), hal ini terjadi karena masyarakat lebih banyak terpapar halhal yang terkait dengan malaria seperti, pengalaman keluarga dan tetangga menghadapi malaria serta berpartisipasi dalam berbagai program pemberantasan malaria.

Faktor georafis, mata pencaharian penduduk, serta tingkat endemitas di Desa Senaning mendorong peneliti untuk melakukan penelitian dengan judul "Gambaran Pengetahuan dan Sikap Warga Desa Senaning Ketungau Hulu Kabupaten Sintang tentang Penyakit Malaria Knowlesi".

Tujuan dilakukan penelitian ini adalah untuk (1) mengetahui karakteristik umum warga warga Desa Senaning Kecamatan Ketungau Hulu Kabupaten Sintang berupa usia, jenis kelamin, pendidikan dan pekerjaan, (2) mengetahui gambaran pengetahuan warga Desa Senaning Kecamatan Ketungau Hulu Kabupaten Sintang tentang penyakit malaria knowlesi, dan (3) mengetahui gambaran sikap warga Desa Senaning Kecamatan Ketungau Hulu Kabupaten Sintang tentang penyakit malaria knowlesi.

\section{METODE}

Penelitian ini adalah penelitian observasional deskriptif. Penelitian dilakukan di Puskesmas Senaning dan Desa Senaning, Kecamatan Ketungau Hulu, Kabupaten Sintang, dari bulan Agustus 2019 sampai dengan Juli 2020. Populasi penelitian ini adalah warga Desa Senaning, Kecamatan Ketungau Hulu yang berbatasan langsung dengan Sarawak. Jumlahnya adalah 1412 jiwa. Sampel dihitung menggunakan rumus Slovin dan didapatkan sampel sebanyak 93 sampel. Kriteria inklusi dalam penelitian ini adalah (1) warga yang terdaftar di Desa Senaning, Kecamatan Ketungau Hulu, Kabupaten Sintang, (2) berusia minimal 17 tahun, dan (3) bersedia menjadi responden penelitian ini. Kriteria ekslusi dalam penelitian ini adalah (1) lansia yang mengalami kepikunan, dan (2) tidak mengisi kuisioner dengan lengkap. Teknik pemilihan sampel dilakukan dengan teknik purposive sampling.

Instrumen penelitian ini adalah kuesioner tentang pengetahuan dan sikap warga tentang penyakit malaria knowlesi sebagai alat ukur yang digunakan dalam pengumpulan data. Kuisioner yang digunakan merupakan hasil modifikasi dari kuisoner penelitian Harahap (2010) dan kuisioner Munisi et al. ( 2019).

Uji validitas kuisioner ini dinilai dengan uji korelasi pearson. Skor yang didapat dari setiap pertanyaan dan pernyataan dikorelasikan dengan skor total variabel yang diukur. Nilai tersebut kemudian dikorelasikan dengan nilai $r$ tabel. Variabel yang diuji (pengetahuan dan sikap tentang malaria knowlesi) dinyatakan valid apabila nilai $r$ yang diperoleh lebih besar dari nilai $r$ tabel dan probabilitas korelasinya $<0,361$. Uji reabilitas menggunakan Alpha cronbach. Hasil uji dikatakan realibel jika nilai Alpha cronbach $>0,6$. Kedua 
kuesioner yang digunakan dalam penelitian ini telah dinyatakan valid dan reliabel karena memiliki nilai $r$ pearson $>0,361$ dan nilai alpa Cronbach $>0,6$.

Data dikumpulkan dari data primer yaitu, wawancara dengan warga Desa Senaning dengan menggunakan kuisioner. Pengumpulan data dilakukan di Desa Senaning, Kecamatan Ketungau Hulu dari tanggal 29 Januari 2020 sampai dengan tanggal 1 Februari 2020 pada pukul 08.00 - 12.00, pukul 13.00 17.00, dan pukul 19.00-21.00. Penelitian dilakukan oleh peneliti dan tiga orang pembantu peneliti yang sebelumnya telah dilakukan pengarahan oleh peneliti.

Penelitian dilakukan dengan kunjungan peneliti ke Puskesmas Senaning untuk mengambil data primer dengan wawancara penduduk Desa Senaning dan masuk kriteria inklusi. Peneliti kemudian melanjutkan penelitian ke Desa Senaning. Pengumpulan data di Desa Senaning dilakukan dengan menyusuri jalan desa, kemudian meminta persetujuan kepada penduduk yang ditemui untuk diwawancara.

Pengolahan data dilakukan melalui tahap editing, coding, entry dan tabulasi data. Data dianalisis dan dibuat dalam bentuk tabel distribusi frekuensi yang selanjutnya dibuat dalam bentuk narasi. Pengambilan data dimulai dengan informed consent serta menjelaskan maksud dan tujuan penelitian kepada subjek. Semua data dan informasi subjek dijaga kerahasiaannya.

\section{HASIL DAN PEMBAHASAN}

\section{A. Karakteristik Responden}

Tabel 1. Karakteristik Responden

\begin{tabular}{llll}
\hline & Karakteristik Responden & $\begin{array}{l}\text { Frekuensi } \\
(\mathrm{n}=93)\end{array}$ & $\begin{array}{l}\text { Persentase } \\
(100 \%)\end{array}$ \\
\hline \multirow{3}{*}{ Usia } & Remaja akhir : 17-25 tahun & 23 & $24,73 \%$ \\
\cline { 2 - 4 } & Dewasa awal : 26-35 tahun & 25 & $26,88 \%$ \\
\cline { 2 - 4 } & Dewasa akhir : 36-45 tahun & 16 & $17,20 \%$ \\
\cline { 2 - 4 } & Lansia awal : 46-55 tahun & 18 & $19,35 \%$ \\
\cline { 2 - 4 } & Lansia akhir : 56-65 tahun & 11 & $11,83 \%$ \\
\hline Jenis Kelamin & Laki-laki & 48 & $51,61 \%$ \\
\cline { 2 - 4 } & Perempuan & 45 & $48,39 \%$ \\
\hline Pendidikan terakhir & Tidak bersekolah/ tidak tamat & 10 & $10,75 \%$ \\
\cline { 2 - 4 } & Tamat SD & 14 & $15,05 \%$ \\
\cline { 2 - 4 } & Tamat SMP & 11 & $11,83 \%$ \\
\cline { 2 - 4 } & Tamat SMA & 26 & $27,96 \%$ \\
\cline { 2 - 4 } & Tamat perguruan tinggi & 32 & $34,41 \%$ \\
\hline Pekerjaan & Petani/ buruh & 32 & $17,41 \%$ \\
\cline { 2 - 4 } & Lain-lain & 12 & $12,20 \%$ \\
\cline { 2 - 4 } & lbu rumah tangga & $11,90 \%$ \\
\cline { 2 - 4 } & Pegawai negeri & & $11,83 \%$ \\
\cline { 2 - 4 } & Pegawai swasta & 12 & \\
\hline
\end{tabular}

Sumber: Data primer, tahun 2020

Hasjlurnal Pernelitiakn menu mukkan bahwa usia responden pada saat penelitian dilakukan paling banyak dewasa awal 26-35 tahun sebanyak 25 
orang $(26,88 \%)$ dan remaja akhir $15-25$ tahun sebanyak 23 orang $(24,73 \%)$. Hal ini dapat dikaitkan dengan keadaan demografi penduduk Ketungau Hulu yang digambarkan sebagai piramida penduduk muda, dan kelompok umur tersebut merupakan kelompok umur terbanyak yang masuk kriteria inklusi. Hasil ini serupa dengan penelitian yang dilakukan oleh Pulungan (2019), dimana didapatkan hasil usia responden terbanyak adalah usia <20 tahun sebanyak 19 orang (25,3\%) dan usia 21-30 tahun sebanyak 17 orang $(22,7 \%)$. Menurut studi yang dilakukan oleh Herdiana et al. (2016), orang dewasa dengan rentang usia 16-45 tahun memiliki risiko 14,0 kali lebih besar terinfeksi malaria daripada kelompok umur $\leq 15$ tahun. Orang dewasa memiliki risiko lebih tinggi terkena malaria knowlesi dibandingkan dengan anak-anak, dikarenakan orang dewasa lebih sering beraktifitas di hutan terkait pekerjaan yang menjadi situs infeksi malaria knowlesi.

Ditemukan bahwa responden yang berjenis kelamin laki-laki sebanyak 48 orang $(51,61 \%)$ dan perempuan sebanyak 45 orang (48,39\%). Responden yang diwawancari lebih banyak laki-laki dari pada responden yang berjenis kelamin perempuan. Hal ini dikarenakan jumlah warga Desa Senaning didominasi oleh laki-laki, dimana jumlah laki-laki adalah 725 orang $(51,35 \%)$ dan perempuan 687 orang $(48,65 \%)$. Menurut studi Herdiana et al. (2016), di daerah dengan tingkat transmisi malaria rendah, pria dewasa merupakan faktor risiko terhadap infeksi malaria. Laki-laki memiliki risiko 12,5 kali lebih besar terinfeksi malaria daripada wanita. Hal ini dikaitkan dengan kegiatan yang dilakukan laki-laki yang lebih sering berkorelasi dengan kegiatan luar ruangan di malam hari sehingga risiko terpapar nyamuk penular malaria lebih besar.

Penelitian ini diikuti oleh responden yang sebagian besar menyelesaikan pendidikan tinggi $(34,41 \%)$ dan SMA (27,96\%). Responden yang tamat perguruan tinggi merupakan responden yang ditemui peneliti di Puskesmas Senaning dan bekerja sebegai petugas kesehatan. Tingkat pendidikan responden di Desa Senaning berhubungan dengan ketersediaan sarana pendididikan. Desa Senaning memiliki empat SD, satu SLTP dan dua SLTA. Hal ini meningkatkan kesadaran akan pendidikan warga Desa Senaning. Seseorang yang memiliki pendidikan tinggi cenderung mempunyai pengetahuan yang lebih baik tentang pencegahan penyakit dan mempunyai kesadaran tinggi terhadap masalah kesehatan. Hasil yang didapatkan berbeda dengan penelitian yang dilakukan Suharjo (2015) di Desa Sukadamai dan Desa Emil Baru, Kecamatan Mantewe, Kabupaten Tanah Bumbu, Provinsi Kalimantan Selatan yang didapatkan hasil tingkat pendidikan yang dominan adalah responden yang tidak tamat sekolah dasar sebanyak 83 orang $(41,5 \%)$ responden. Meskipun tingkat pendidikan responden kedua penelitan tersebut berbeda, tingkat pengetahuan dan sikap yang didapatkan kedua penelitian tersebut baiknya. Hal ini dikarenakan Desa Sukadamai dan Desa Emil Baru merupakan daerah endemis malaria dimana sebagian besar $(98,0 \%)$ responden pernah mendengar dan mengetahui tentang malaria. Daerah endemis memungkinkan penduduknya terpapar informasi tentang malaria baik melalui pengalaman maupun melalui penyuluhan pemberantasan penyakit malaria. 
Responden penelitian banyak yang bekerja sebagai petani/ buruh yaitu, 32 orang $(34,41 \%)$. Hal ini dikarenakan banyaknya lahan pertanian dan perkebunan di Desa Senaning. Grigg et al. (2017) menyebutkan salah satu faktor risiko malaria knowlesi adalah pekerjaan sebagai petani. Pekerjaan spesifik seperti pekerja perkebunan kelapa sawit dan penebang hutan meningkatkan risiko infeksi. Responden yang bekerja sebagai pegawai negeri sebanyak 12 orang $(12,90 \%)$ adalah petugas kesehatan di Puskesmas Senaning. Responden dengan kategori pekerjaan lain-lain berjumlah 22 orang $(23,66 \%)$ yang sebagian besar (20 orang) merupakan petugas kesehatan di Puskesmas Senaning. Pekerjaan yang lebih banyak dilakukan di dalam ruangan berkorelasi dengan penurunan risiko infeksi. Menurut studi yang dilakukan Herdiana (2016) individu dengan lokasi tempat kerja di hutan atau dekat hutan serta membutuhkan menginap semalaman di hutan memiliki risiko 7,9 kali lebih tinggi terinfeksi malaria dibanding individu yang tempat kerjanya jauh dari hutan.

Tabel 2. Distribusi Responden Berdasarkan Tingkat Pengetahuan

\begin{tabular}{|c|c|c|}
\hline $\begin{array}{l}\text { Tingkat } \\
\text { Pengetahuan }\end{array}$ & Jumlah & Persentase \\
\hline Baik & 32 & $34,4 \%$ \\
\hline Cukup & 46 & $49,5 \%$ \\
\hline Kurang & 15 & $16,1 \%$ \\
\hline $\begin{array}{l}\text { Jumlah } \\
\text { Keseluruhan }\end{array}$ & 93 & $100 \%$ \\
\hline
\end{tabular}

Sumber: Data primer, tahun 2019

Responden yang terlibat dalam penelitian ini berjumlah 46 orang $(49,5 \%)$. Dari jumlah ini, 32 orang $(34,4)$ memiliki pengetahuan cukup, dan pengetahuan baik; serta 15 orang (16,1\%) memiliki pengetahuan kurang tentang malaria knowlesi. Tingkat pengetahuan responden pada penelitian ini berbeda dengan Hikmawati (2018) yang melaporkan bahwa 71 orang (84,5\%) memiliki pengetahuan kurang. Sebagian responden dalam penelitian ini bekerja sebagai petugas kesehatan. Mereka memiliki pengaruh terhadap tingkat pengetahuan karena memiliki kesempatan lebih besar bersentuhan dengan kasus malaria, sehinga cenderung memiliki pengetahuan baik. Hal ini juga terjadi karena karakteristik responden dan waktu penelitian yang berbeda (2016). Penelitian yang dilakukan Hikmawati (2018) diikuti oleh responden yang dominan berusia 4145 tahun, jenis kelamin perempuan, tamat SD, dan bekerja sebagai petani. Waktu penelitian yang berselang empat tahun juga memiliki pengaruh terhadap skor pengetahuan, serta kemajuan teknologi mempermudah seseorang mengakses pengetahuan dan menambah wawasan. 
Tabel 3. Rekapitulasi Jawaban Tingkat Pengetahuan Responden

\begin{tabular}{|c|c|c|c|}
\hline Pertanyan & Tanggapan & Frekuensi & $\%$ \\
\hline \multirow[t]{2}{*}{ Apakah malaria itu? } & Benar & 53 & 56,99 \\
\hline & Salah & 40 & 43,01 \\
\hline \multirow{2}{*}{$\begin{array}{l}\text { Dari kelompok apakah parasite yang dapat } \\
\text { menyebabkan malaria pada manusia? }\end{array}$} & Benar & 58 & 62,37 \\
\hline & Salah & 35 & 37,63 \\
\hline \multirow{2}{*}{$\begin{array}{l}\text { Hewan apakah yang dapat menyebabkan } \\
\text { penularan malaria ke manusia? }\end{array}$} & Benar & 91 & 97,85 \\
\hline & Salah & 2 & 2,15 \\
\hline \multirow{2}{*}{$\begin{array}{l}\text { Terkena gigitan nyamuk dan melalui perantara } \\
\text { jarum suntik bekas dapat menyebabkan? }\end{array}$} & Benar & 70 & 75,27 \\
\hline & Salah & 23 & 24,73 \\
\hline \multirow[t]{2}{*}{ Apakah Plasmodium knowlesi itu? } & Benar & 35 & 37,63 \\
\hline & Salah & 58 & 62,37 \\
\hline \multirow{2}{*}{$\begin{array}{l}\text { Plasmodium knowlesi dapat ditemukan pada } \\
\text { hewan, hewan apakah itu? }\end{array}$} & Benar & 57 & 61,29 \\
\hline & Salah & 36 & 38,71 \\
\hline \multirow{2}{*}{$\begin{array}{l}\text { Menggunakan anti nyamuk bakar dan oles serta } \\
\text { menggunakan kelambu pada malam hari } \\
\text { merupakan cara terbaik untuk? }\end{array}$} & Benar & 82 & 88,17 \\
\hline & Salah & 11 & 11,83 \\
\hline \multirow{2}{*}{$\begin{array}{l}\text { Kapan nyamuk penular malaria knowlesi aktif } \\
\text { menggigit manusia? }\end{array}$} & Benar & 59 & 63,44 \\
\hline & Salah & 34 & 36,56 \\
\hline \multirow{2}{*}{$\begin{array}{l}\text { Apa gejala khas dari penyakit malaria knowlesi } \\
\text { pada manusia? }\end{array}$} & Benar & 58 & 62,37 \\
\hline & Salah & 35 & 37,63 \\
\hline
\end{tabular}

Sumber: Data primer, tahun 2019

Sebanyak 53 orang (56,9\%) responden mengetahui malaria adalah infeksi yang disebabkan oleh Plasmodium sp. Pada pertanyaan kedua sebanyak 58 orang $(62,4 \%)$ mengetahui kelompok parasit yang menyebabkan malaria adalah Plasmodium. Hal ini berbeda dengan penelitian yang dilakukan oleh Randy et al. (2013) yang menyebutkan bahwa 85 orang $(70,8 \%)$ responden tidak mengetahui parasit penyebab malaria. Randy et al. (2013) menjabarkan bahwa $80 \%$ responden dalam penelitiannya tidak pernah mendapatkan penyuluhan tentang malaria. Penelitian tersebut juga melaporkan bahwa tingkat pengetahuan warga masih rendah. Hal tersebut menjadi faktor perbedaan jawaban responden.

Penelitian ini menunjukan hasil bahwa 91 responden $(97,8 \%)$ mengetahui bahwa malaria ditularkan melalui nyamuk. Sebanyak 70 responden $(75,3 \%)$ mengetahui bahwa malaria dapat menular ke manusia melalui gigitan nyamuk dan melalui perantara jarum suntik bekas. Hasil serupa ditunjukan pula oleh Akay et al. (2015) di Minahasa Tenggara yang melaporkan bahwa 193 responden $(99,5 \%)$ mengetahui tentang gigitan nyamuk sebagai penyebab malaria. Temuan serupa juga ditunjukan oleh Lombogia et al. (2015) di Minahasa Tenggara, yang melaporkan bahwa 95 orang $(100 \%)$ setuju kalau penularan malaria melalui gigitan nyamuk. Kesamaan yang ditunjukan ketiga penelitian tersebut dipengaruhi oleh program pemerintah untuk menurunkan kejadian malaria di lokasi endemik. Hal tersebut meningkatkan pengetahuan warga mengenai agen penular malaria.

Penelitian ini menemukan bahwa 82 orang $(88,17 \%)$ responden mengetahui penggunaan anti nyamuk bakar dan oles, serta penggunaan kelambu pada malam hari sebagai pencegah penularan malaria knowlesi. Hal ini serupa dengan penelitian yang dilakukan oleh Randy et al. (2013) di 
Minahasa Utara yang mendapatkan hasil 84 orang $(70 \%)$ responden tahu bahwa kelambu dapat mencegah malaria. Hasil serupa juga ditujunjukan pada penelitian yang dilakukan oleh Lombogia et al. (2015), 92 orang $(96,8 \%)$ responden mengetahui cara pencegahan malaria yang meliputi penggunaan kelambu, obat pembasmi nyamuk pada malam hari, menggunakan repelen dan tidak tidak beraktifikas keluar pada malam hari. Pengetahuan mengenai pencegahan malaria tersebut menjadi alasan penurunan angka kejadian malaria di daerah tersebut.

Penelitian ini menunjukan hasil 59 orang $(63,44 \%)$ responden mengetahui bahwa nyamuk penular malaria knowlesi aktif menggigit pada malam hari. Hal ini dibandingkan dengan penelitian yang dilakukan oleh Akay et al. (2015) yang mendapatkan hasil serupa, 112 orang $(57,7 \%)$ responden mengetahui waktu menggigit nyamuk penular penyakit malaria terjadi pada malam hari. Persepsi yang benar mengenai waktu nyamuk menggigit dapat mendorong pencegahan terhadap malaria dan penggunaan kelambu yang baik dan benar.

Sebanyak 39 orang (41,9\%) responden penelitian ini menjawab bahwa Plasmodium knowlesi adalah virus yang menyebabkan malaria knowlesi. Sebanyak 35 orang $(37,6 \%)$ responden menjawab 'benar' bahwa Plasmodium knowlesi adalah parasit yang menyebabkan penyakit malaria knowlesi, dan 19 orang $(20,4 \%)$ lainya menjawab 'tidak tahu' apa itu Plasmodium knowlesi. Hasil penelitian ini menunjukan bahwa 57 orang $(61,29 \%)$ responden mengetahui hewan yang menjadi hospes malaria knowlesi. Sebanyak 58 responden $(62,37 \%)$ mengetahui bahwa gejala khas yang ditimbulkan malaria knowlesi adalah demam harian tiap 24 jam sekali.
Shaqiena \& Mustika (2020) menyebutkan pengetahuan warga tentang malaria berpengaruh kepada proses penyebaran penyakit malaria. Pengetahuan yang baik akan mendukung adanya penyikapan positif terhadap kejadian malaria yang baik, dan akan melakukan respon terhadap kejadian malaria secara positif. Respon yang positif akan mendorong melakukan upaya-upaya pencegahan agar malaria tidak membahayakan dirinya dan orang-orang di sekitarnya.

Hasil penelitian yang dilakukan oleh Prastiawan (2019) di Kecamatan Watulimo Kabupaten Trenggalek menyebutkan bahwa orang yang berpengetahuan kurang memiliki risiko 11,946 kali lebih besar terkena malaria impor dibandingkan dengan orang yang memiliki pengetahuan tentang malaria dan pencegahannya.

Tabel 4. Distribusi Responden Berdasarkan Tingkat Sikap

\begin{tabular}{lll}
\hline $\begin{array}{l}\text { Tingkat } \\
\text { Pengetahuan }\end{array}$ & Jumlah & Persentase \\
\hline Baik & 26 & $27,95 \%$ \\
Cukup & 64 & $68,82 \%$ \\
Kurang & 3 & $3,23 \%$ \\
\hline Jumlah & 93 & $100 \%$ \\
\multicolumn{3}{l}{ Keseluruhan } \\
\multicolumn{3}{l}{ Sumber: Data primer, tahun 2019}
\end{tabular}

Diukur dengan menggunakan kuisioner Skala Likert yang terdiri dari delapan penyataan $68,8 \%$ dari responden yang mengikuti penelitian ini memiliki sikap 'cukup' tentang malaria knowlesi. Temuan ini serupa dengan Yulidar \& Wilya (2016), yang menemukan 75 responden (100\%) yang memiliki sikap yang baik mengenai malaria. Persamaan tingkat sikap pada kedua jenis penelitian dipengaruhi faktor persamaan pada tingkat pengetahuan. Penelitian yang dilakukan oleh Yulidar \& Wilya (2016) menunjukan bahwa sebagian besar (72\%) memiliki pengetahuan yang baik. Seseorang yang dibekali dengan 
pengetahuan memiliki kesempatan lebih besar untuk menerapkan sikap yang baik dalam kesehariannya.

Tabel 5. Rekapitulasi Jawaban Sikap Responden

\begin{tabular}{|c|c|c|c|}
\hline Variabel & Tanggapan & $\begin{array}{l}\text { Frekuensi } \\
(\mathrm{n}=93)\end{array}$ & $\begin{array}{l}\text { Persentase } \\
(100 \%)\end{array}$ \\
\hline $\begin{array}{l}\text { Malaria adalah penyakit serius } \\
\text { dan mengancam jiwa. }\end{array}$ & $\begin{array}{l}\text { Sangat setuju } \\
\text { Setuju } \\
\text { Tidak setuju } \\
\text { Sangat tidak setuju }\end{array}$ & $\begin{array}{r}33 \text { orang } \\
45 \text { orang } \\
12 \text { orang } \\
3 \text { orang }\end{array}$ & $\begin{array}{r}35,5 \% \\
48,4 \% \\
12,9 \% \\
3,2 \%\end{array}$ \\
\hline $\begin{array}{l}\text { Cara terbaik agar saya tidak } \\
\text { terkena malaria adalah } \\
\text { menghindari gigitan nyamuk. }\end{array}$ & $\begin{array}{l}\text { Sangat setuju } \\
\text { Setuju } \\
\text { Tidak setuju }\end{array}$ & $\begin{array}{r}47 \text { orang } \\
40 \text { orang } \\
6 \text { orang }\end{array}$ & $\begin{array}{r}50,5 \% \\
43 \% \\
6,5 \%\end{array}$ \\
\hline $\begin{array}{l}\text { Saya yakin setiap orang dapat } \\
\text { terkena malaria. }\end{array}$ & $\begin{array}{l}\text { Sangat setuju } \\
\text { Setuju } \\
\text { Tidak setuju } \\
\text { Sangat tidak setuju }\end{array}$ & $\begin{array}{r}19 \text { orang } \\
47 \text { orang } \\
24 \text { orang } \\
3 \text { orang }\end{array}$ & $\begin{array}{r}20,4 \% \\
50,5 \% \\
25,8 \% \\
3,2 \%\end{array}$ \\
\hline $\begin{array}{l}\text { Tidur menggunakan kelambu } \\
\text { dapat mencegah saya terkena } \\
\text { malaria. }\end{array}$ & $\begin{array}{l}\text { Sangat setuju } \\
\text { Setuju } \\
\text { Tidak setuju }\end{array}$ & $\begin{array}{r}54 \text { orang } \\
35 \text { orang } \\
4 \text { orang }\end{array}$ & $\begin{array}{r}58,1 \% \\
37,6 \% \\
4,3 \%\end{array}$ \\
\hline $\begin{array}{l}\text { Saya dapat memiliki risiko besar } \\
\text { terkena malaria jika saya bekerja } \\
\text { dan bermalam di hutan atau } \\
\text { kebun. }\end{array}$ & $\begin{array}{l}\text { Sangat setuju } \\
\text { Setuju } \\
\text { Tidak setuju } \\
\text { Sangat tidak setuju }\end{array}$ & $\begin{array}{r}28 \text { orang } \\
39 \text { orang } \\
23 \text { orang } \\
3 \text { orang }\end{array}$ & $\begin{array}{r}30,1 \% \\
41,9 \% \\
24,7 \% \\
3,2 \%\end{array}$ \\
\hline $\begin{array}{l}\text { Berbahaya ketika obat malaria } \\
\text { tidak dihabiskan. }\end{array}$ & $\begin{array}{l}\text { Sangat setuju } \\
\text { Setuju } \\
\text { Tidak setuju } \\
\text { Sangat tidak setuju }\end{array}$ & $\begin{array}{r}33 \text { orang } \\
43 \text { orang } \\
16 \text { orang } \\
1 \text { orang }\end{array}$ & $\begin{array}{r}35,5 \% \\
46,2 \% \\
17,2 \% \\
1,1 \%\end{array}$ \\
\hline $\begin{array}{l}\text { Saya harus pergi ke puskesmas/ } \\
\text { klinik untuk pemeriksaan darah } \\
\text { saat saya curiga saya menderita } \\
\text { malaria. }\end{array}$ & $\begin{array}{l}\text { Sangat setuju } \\
\text { Setuju } \\
\text { Tidak setuju }\end{array}$ & $\begin{array}{r}61 \text { orang } \\
31 \text { orang } \\
1 \text { orang }\end{array}$ & $\begin{array}{r}65,6 \% \\
33,3 \% \\
1,1 \%\end{array}$ \\
\hline $\begin{array}{l}\text { Saya dapat memiliki risiko } \\
\text { terkena malaria knowlesi jika } \\
\text { saya memelihara monyet ekor } \\
\text { panjang atau monyet ekor babi. }\end{array}$ & $\begin{array}{l}\text { Sangat setuju } \\
\text { Setuju } \\
\text { Tidak setuju } \\
\text { Sangat tidak setuju }\end{array}$ & $\begin{array}{r}31 \text { orang } \\
41 \text { orang } \\
16 \text { orang } \\
5 \text { orang }\end{array}$ & $\begin{array}{r}33,3 \% \\
44,1 \% \\
17,2 \% \\
5,4 \% \\
\end{array}$ \\
\hline
\end{tabular}

Penelitian ini menunjukan bahwa sebagian besar responden setuju jika malaria adalah penyakit serius dan mengancam jiwa. Hal ini berkaitan dengan pengalaman terkait malaria sebelumnya dan persepsi bahwa malaria adalah penyakit parah yang dapat membuat seseorang mengidap penyakit psikologis. Hasil penelitian ini serupa dengan Shaqiena \& Mustika
(2020) yang melaporkan bahwa terdapat 33 orang (94\%) responden yang setuju jika malaria adalah penyakit yang berbahaya. Hasil serupa yang didapatkan pada dua penelitian ini dipengaruhi faktor persamaan tingkat sikap, dimana kedua penelitian samasama mendapatkan hasil kategori sikap cukup. 
Sebagian besar responden penelitian ini 'sangat setuju' bahwa cara terbaik pencegahan malaria adalah menghindari gigitan nyamuk. Hal ini berbeda dengan penelitian Rahayu et al. (2016) di Desa Miing Kabupaten Tanah Bumbu, yang menunjukkan bahwa $40 \%$ responden 'tidak setuju' mencegah penyakit malaria dengan cara menghindari diri dari gigitan nyamuk. Perbedaan ini dipengaruhi tingkat pendidikan dan tingkat pengetahuan yang masih rendah di daerah tersebut sehingga kesadaran mencegah penyakit malaria masih rendah.

Sebagian besar responden penelitian ini 'setuju' bahwa setiap orang dapat terkena malaria. Hal ini dikaitkan dengan pengalaman penduduk terhadap malaria, dimana penderita malaria sebelumnya berasal dari berbagai latar belakang yang berbeda-beda. Hasil yang diperoleh serupa dengan penelitian Abate et al. (2013) dimana didapatkan hasil lebih dari $90 \%$ responden setuju bahwa malaria dapat menginfeksi laki-laki dan perempuan dari segala rentang usia. Sikap masyarakat terhadap faktor risiko malaria dipengaruhi oleh pengalaman ketika mereka berhadapan dengan orang-orang disekitarnya yang terinfeksi malaria.

Penelitian ini menunjukan bahwa sebagian besar responden 'sangat setuju' ketika tidur mereka menggunakan kelambu untuk mencegah malaria. Pembagian kelambu yang dilakukan pemerintah merupakan faktor yang meningkatkan sikap positif masyarakat akan penggunaan kelambu. Hal ini berbeda dengan penelitian yang dilakukan Septiyani (2018) yang mendapatkan 44 responden (44\%) yang memiliki 'sikap negatif' terhadap penggunaan kelambu.

Sebagian besar responden dalam penelitian ini setuju bahwa bekerja dan bermalam di hutan atau kebun meningkatkan risiko terkena malaria. Menurut warga bermalam di hutan atau kebun merupakan pengalaman yang kurang menyenangkan karena banyak nyamuk dan serangga. Hasil ini serupa dengan penelitian Munisi et al. (2019) yang mendapatkan hasil 142 orang $(51,26 \%)$ 'setuju' bahwa bekerja dan bermalam di hutan atau kebun meningkatkan risiko terkena malaria. Bekerja dilingkungan hutan atau kebun sering diasosiasikan dengan risiko terpapar nyamuk. Hal ini memberikan pandangan kepada masyarakat bahwa bermalam di hutan atau kebun meningkatkan risiko terkena malaria.

Sebagian besar responden dalam penelitian ini setuju bahwa jika obat malaria tidak dihabiskan akan berbahaya. Hal ini serupa dengan hasil yang didapatkan sebagian besar Munisi et al. (2019) dimana terdapat 152 orang $(54,87 \%)$ responden yang setuju bahwa jika obat malaria tidak dihabiskan, akan berbahaya. Sikap kepatuhan pasien dalam meminum obat dapat dipengaruhi oleh edukasi dokter ketika pasien berobat. Selain itu, edukasi dari pemerintah mengenai terapi malaria, seperti tidak membeli obat malaria tanpa resep dokter berpengaruh terhadap sikap disiplin masyarakat dalam konsumsi obat malaria.

Penelitian ini menunjukan bahwa sebagian besar responden sangat setuju bahwa ketika curiga terkena malaria harus pergi ke puskesmas/ klinik untuk melakukan pemeriksaan darah. Sikap positif ini didasari dengan adanya kesadaran masyarakat tentang pentingnya menjaga kesehatan dan mengobati penyakit sejak dini. Hal ini juga didukung dengan dekatnya warga Desa Senaning dengan fasilitas kesehatan, dimana Puskesmas Senaning berlokasi dekat dengan desa, dengan akses yang mudah dijangkau. Hasil ini serupa dengan penelitian yang 
dilakukan Shaqiena \& Mustika (2020), 34 responden (97\%) responden setuju kalau penderita malaria diambil darahnya untuk diperiksa. Kesadaran masyarakat untuk berobat ke fasilitas kesehatan ketika mengalami gejala malaria berkorelasi dengan sikap bahwa malaria merupakan penyakit serius dan pengetahuan mengenai tanda dan gelaja malaria. Kesadaran akan bahaya malaria dalam meningkatkan sikap positif untuk mencari pertolongan ke fasilitas kesehatan ketika curiga terkena malaria.

Sebagian besar responden penelitian ini setuju bahwa memelihara monyet ekor panjang atau monyet ekor babi berisiko terkena malaria knowlesi. Istilah yang sering didengar oleh masyarakat terkait malaria knowlesi adalah malaria berok. Kata 'berok' adalah bahasa setempat untuk menggambarkan monyet. Istilah malaria berok ini diasosiasikan warga dengan resiko terkena malaria jika memelihara monyet. Selain itu, memelihara monyet juga dihubungkan dengan gambaran kurang bersih dan rapi sehingga berpotensi mengundang nyamuk.

Mayoritas responden dari Desa Senaning, Kecamatan Ketungau Hulu, Kabupaten Sintang memiliki pengetahuan dan sikap cukup tentang malaria knowlesi. Hal ini dihubungkan dengan kinerja Puskesmas Senaning Kecamatan Ketungau Hulu yang aktif mensosialisasikan mengenai isu kesehatan yang terjadi saat itu. Pada saat dilakukan penelitian, sosialisasi mengenai malaria telah jarang dilakukan karena angka kejadian yang kecil. Pada tahun 2019 hanya ada satu pasien malaria yang tercatat di Puskesmas setempat. Hal ini terjadi karena keberhasilan program kelambu yang dilakukan pemerintah Kabupaten Sintang.
Angka kejadian malaria yang kecil juga dipengaruhi oleh perilaku bersih yang diterapkan warga. Selama penelitian, peneliti tidak menemukan kandang ternak berada bersebelahan dengan rumah tinggal. Sebagian besar rumah warga memiliki konstruksi yang tertutup. Jalan desa dan pekarangan penduduk cenderung bersih dan jarang ditemukan sampah. Rumah warga cenderung berkumpul di sepanjang jalan desa, masih terdapat kebun di dalam pedesaan. Namun, perumahan cenderung sedikit di daerah yang berdekatan dengan kebun.

Di sisi lain diagnosis malaria yang digunakan di Puskesmas Senaning adalah RDT CareStart ${ }^{\mathrm{TM}}$ yang mengandung reagen pLDH untuk mendeteksi Plasmodium secara umum dan PfHRP2 yang mendeteksi $P$. falciparum. Hal ini mengakibatkan diagnosis untuk malaria knowlesi tidak dapat ditegakkan. Menurut Barber et al. (2017), Plasmodium knowlesi pada saat ini diperkirakan merupakan jenis Plasmodium yang dominan di berbagai kabupaten di wilayah bagian barat Indonesia. Bukti terbatas di daerah ini menunjukan bahwa semua kasus malaria knowlesi didiagnosis secara mikroskopis sebagai malaria falciparum atau malaria vivax.

\section{KESIMPULAN}

Hasil dari penelitian tentang gambaran pengetahuan dan sikap warga Desa Senaning, Kecamatan Ketungau Hulu, Kabupaten Sintang tentang penyakit malaria knowlesi adalah pengetahuan warga Desa Senaning tentang malaria knowlesi sebagian besar cukup (49,5\%). Gambaran sikap warga Desa Senaning tentang malaria knowlesi sebagian besar cukup (68,8\%). Karakteristik masyarakat yang menjadi responden sebagian besar berjenis 
kelamin laki-laki dengan usia dewasa awal (26-35 tahun) dan remaja akhir (17-25 tahun), berpendidikan terakhir tamat perguruan tinggi dan pekerjaan petani/ buruh.

\section{REKOMENDASI}

Pengetahuan dan sikap warga Desa Senaning Kecamatan Ketungau Hulu tergolong dalam kategori cukup, hal ini dapat menjadi bahan evaluasi bagi pemerintah untuk meningkatkan program edukasi dan pencegahan malaria kepada masyarakat sebagai langkah preventif kejadian malaria knowlesi.

Kejadian malaria knowlesi Malaysia sudah cukup banyak dan Desa Senaning Kecamatan Ketungau Hulu merupakan daerah yang berbatasan langsung dengan Sarawak Malaysia. Hal ini menyebabkan masyarakatnya berpotensi terinfeksi malaria knowlesi sehingga sebaiknya dilakukan penyuluhan khusus malaria knowlesi

$$
\text { Kejadian malaria di Desa }
$$

Senaning sudah sangat sedikit. Hal ini dapat dikarenakan program eliminasi malaria yang sudah berhasil, namun juga dapat dikarenakan underdiagnosis penderita malaria akibat peralatan diagnosis yang kurang memadai. Kejadian ini dapat dicegah dengan menyediakan peralatan diagnosis malaria sesuai standar baku emas, agar pasien dengan dugaan malaria, segera mendapat terapi yang tepat.

Masyarakat dapat melakukan pencegahan terhadap malaria dengan menghindari gigitan nyamuk, tidur menggunakan kelambu, tidak bermalam di hutan/ kebun dan tidak memelihara monyet ekor panjang dan monyet ekor pendek, sehingga setiap anggota masyarakat menjadi agen perubahan dalam pencegahan malaria.
Kewaspadaan terhadap malaria juga dapat dilakukan dengan memeriksakan diri ke fasilitas kesehatan ketika curiga terkena malaria dan mematuhi terapi yang diberikan sesuai petunjuk petugas kesehatan.

Peneliti selanjutnya dapat melakukan replikasi penelitian ini dengan melakukan penelitian serupa pada daerah perbatasan Indonesia dan Malaysia lainnya ataupun daerah endemik penyakit menular lainya.

\section{DAFTAR PUSTAKA}

Abate, A., Degarege, A., \& Erko, B. (2013). Community knowledge, attitude and practice about malaria in a low endemic setting of Shewa Robit Town, northeastern Ethiopia. BMC Public Health. https://doi.org/10.1186/14712458-13-312

Akay, C. S., Tuda, J. S. B., \& Pijoh, V. D. (2015). Gambaran pengetahuan masyarakat tentang penyakit malaria di Kecamatan Silian Raya Kabupaten Minahasa Tenggara. Jurnal E-Biomedik. https://doi.org/10.35790/ebm.3.1.2 015.7421

Ambarita, L. P. (2014). Plasmodium knowlesi: distribution, microscopic features, symptoms and potential vector. Jurnal Ekologi Kesehatan.

Asmara, I. G. Y. (2019). Infeksi malaria Plasmodium knowlesi pada manusia. Jurnal Penyakit Dalam Indonesia.

https://doi.org/10.7454/jpdi.v5i4.22 4

Badan Pusat Statistik Kabupaten Sintang, 2019, Kecamatan Ketungau Hulu dalam angka 2019. Badan Pusat Statistik Kabupaten Sintang.

Barber, B. E., Rajahram, G. S., Grigg, 
M. J., William, T., \& Anstey, N. M. (2017). World Malaria Report: time to acknowledge Plasmodium knowlesi malaria. Malaria Journal. https://doi.org/10.1186/s12936017-1787-y

Dinas Kesehatan Prov. Kalbar (2018). Profil Kesehatan Provinsi Kalimantan Barat 2017. Dinas Kesehatan Prov Kalbar. Pontianak.

Faust, C., \& Dobson, A. P. (2015). Primate malarias: Diversity, distribution and insights for zoonotic Plasmodium. One Health. https://doi.org/10.1016/j.onehlt.20 15.10.001

Forero, D. A., Chaparro, P. E., Vallejo, A. F., Benavides, Y., Gutiérrez, J. B., Arévalo-Herrera, M., \& Herrera, S. (2014). Knowledge, attitudes and practices of malaria in Colombia. Malaria Journal. https://doi.org/10.1186/14752875-13-165

Grigg, M. J., Cox, J., William, T., Jelip, J., Fornace, K. M., Brock, P. M., von Seidlein, L., Barber, B. E., Anstey, N. M., Yeo, T. W., \& Drakeley, C. J. (2017). Individuallevel factors associated with the risk of acquiring human Plasmodium knowlesi malaria in Malaysia: a case-control study. The Lancet Planetary Health. https://doi.org/10.1016/S25425196(17)30031-1

Harahap, U.H. (2010). Gambaran Prilaku Masyarakat dalam Penanggulangan Malaria di Kelurahan Penyabungan II Kecamatan Penyabungan Kota Kabupaten Mandailing Natal, Fakultas Kesehatan Masyarakat, Universitas Sumatera Utara, (Skripsi).

Hazrian, R. (2011). Identifikasi status
dan
luas
lahan untuk pengembangan komoditas pertanian di kawasan perbatasan Kabupaten Sintang. Perkebunan Dan Lahan Tropika.

Herdiana, H., Cotter, C., Coutrier, F. N., Zarlinda, I., Zelman, B. W., Tirta, Y. K., Greenhouse, B., Gosling, R. D., Baker, P., Whittaker, M., \& Hsiang, M. S. (2016). Malaria risk factor assessment using active and passive surveillance data from Aceh Besar, Indonesia, a low endemic, malaria elimination setting with Plasmodium knowlesi, Plasmodium vivax, and Plasmodium falciparum. Malaria Journal.

https://doi.org/10.1186/s12936016-1523-z

Hikmawati, R.A. (2018) Gambaran Pengetahuan, Sikap, dan Perilaku Masyarakat mengenai Pencegahan Penyakit Malaria di Kelurahan Sagatani Kecamatan Singkawang Selatan. Jurnal Proners., 3(1).

Lombogia, P. J., Pijoh, V. D., Wahongan, G. J. P., \& Tuda, J. S. B. (2015). Pengetahuan masyarakat di Desa Tombatu I Kecamatan Tombatu Kabupaten Minahasa Tenggara Tentang penyakit malaria. Jurnal $E$ Biomedik.

https://doi.org/10.35790/ebm.3.1.2 015.7502

Millar, S. B., \& Cox-Singh, J. (2015). Human infections with Plasmodium knowlesi-zoonotic malaria. In Clinical Microbiology and Infection. https://doi.org/10.1016/j.cmi.2015. 03.017

Munisi, D. Z., Nyundo, A. A., \& Mpondo, B. C. (2019). Knowledge, attitude and practice towards malaria among symptomatic patients 
attending Tumbi Referral Hospital: A cross-sectional study. PLOS ONE.

https://doi.org/10.1371/journal.pon e.0220501

Notoadmodjo, S. (2012). Promosi kesehatan \& prilaku kesehatan. Jakarta: EGC.

Paul M. Arguin, K. R. T. (2013). Malaria - Chapter 3 - 2014 Yellow Book | Travelers' Health | CDC. In Yellow Book | Travelers' Health | CDC.

Pemerintah Kabupaten Sintang Dinas Kesehatan. (2016). Profil kesehatan Kabupaten Sintang tahun 2015. Pemerintah Kabupaten Sintang Dinas Kesehatan, Sintang.

Prastiawan, A. (2019). Mobility And Behavior Influences On Import Malaria In The Kecamatan Watulimo Kabupaten Trenggalek. Jurnal Kesehatan Lingkungan, 11(2), 91.

https://doi.org/10.20473/jkl.v11i2.2 019.91-98

Pulungan, M. (2019). Hubungan pengetahuan ,sikap dan tindakan masyarakat terhadap kejadian penyakit malaria di Desa Tambiski Kecamatan Nagajuang Kabupaten Mandailing Natal, Poltekes Kemenkes Medan, Medan, (Skripsi).

Rahayu, N., Hidayat, S., Sulasmi, S., \& Suryatinah, Y. (2016). Kontribusi pekerja hutan terhadap kejadian malaria di Desa Temunih Kecamatan Kusan Hulu Kabupaten Tanah Bumbu Provinsi Kalimantan Selatan. J.Health.Epidemiol. Commun.Dis.

Randy, T., Ottay, R., \& Palandeng, H. (2013). Gambaran pengetahuan masyarakat tentang pencegahan penyakit malaria di Desa Tatelu
Kecamatan Dimembe. Jurnal Kedokteran Komunitas Dan Tropik, 1(4).

Septiyani, D., Wuryanto, M.A., Udiyono, A., 2018, Gambaran Pengetahuan, Sikap, dan Perilaku Pemakaian Kelambu Berinsektisida Tahan Lama (KBTL) (studi di wilayah kerja puskesmas Kaligensing Kabupaten Purworejo). Jurnal kesehatan masyarakat., 6(5): 259266.

Setiadi, W., Sudoyo, H., Trimarsanto, H., Sihite, B. A., Saragih, R. J., Juliawaty, R., Wangsamuda, S., Asih, P. B. S., \& Syafruddin, D. (2016). A zoonotic human infection with simian malaria, Plasmodium knowlesi, in Central Kalimantan, Indonesia. Malaria Journal. https://doi.org/10.1186/s12936016-1272-z

Shaqiena, A., \& Mustika, S. Y. (2020). Pengetahuan, sikap dan perilaku masyarakat terhadap malaria di wilayah kerja Puskesmas Hanura. Jurnal Analis Kesehatan. https://doi.org/10.26630/jak.v8i2.1 861

Singh, B., \& Daneshvar, C. (2013). Human infections and detection of plasmodium knowlesi. In Clinical Microbiology Reviews. https://doi.org/10.1128/CMR.0007 9-12

Suharjo, S. (2015). Pengetahuan sikap dan perilaku masyarakat tentang malaria di daerah endemis Kalimantan Selatan. Media Penelitian Dan Pengembangan Kesehatan. https://doi.org/10.22435/mpk.v25i 1.4093.23-32

World Health Organization, \& University of California. (2015). Progress towards elimination in 
Malaysia. In Eliminating malaria:

case study 8.

Yulidar, \& Wilya, V. (2016).

Pengetahuan, Sikap, dan Perilaku terhadap Malaria pada Masyarakat

di Kecamatan alue Bilie,

Kabupaten Nagan Raya, Aceh.

J.Health.Epidemiol.Commun.Dis.

2(1), 28-32. 